\title{
Diastolic dysfunction contributes to impaired cardiorespiratory fitness in patients with lung cancer and reduced lung function following chest radiation
}

\section{Georgia Thomas ( $\sim$ Georgia.thomas@vcuhealth.org )}

VCU Health: Virginia Commonwealth University Health System https://orcid.org/0000-0002-8303-258X Justin Canada

VCU Health: Virginia Commonwealth University Health System

Elisabeth Weiss

VCU Health: Virginia Commonwealth University Health System

Cory Trankle

VCU Health: Virginia Commonwealth University Health System

\section{Salvatore Carbone}

VCU Health: Virginia Commonwealth University Health System

Ryan Garten

VCU: Virginia Commonwealth University

\section{Ronald Evans}

VCU: Virginia Commonwealth University

\section{Benjamin VanTassell}

VCU Health: Virginia Commonwealth University Health System

\section{Antonio Abbate}

VCU Health: Virginia Commonwealth University Health System

Hayley Billingsley

VCU Health: Virginia Commonwealth University Health System

\section{Research Article}

Keywords: lung cancer, radiotherapy, cardiorespiratory fitness, N-terminal pro-brain natriuretic peptide

Posted Date: May 5th, 2021

DOl: https://doi.org/10.21203/rs.3.rs-481452/v1

License: (c) (i) This work is licensed under a Creative Commons Attribution 4.0 International License. Read Full License 
Version of Record: A version of this preprint was published at Lung on July 8th, 2021. See the published version at https://doi.org/10.1007/s00408-021-00454-6. 


\section{Abstract}

Cardiorespiratory fitness (CRF) is a robust and independent predictor of cardiovascular health and overall mortality. Patients with lung cancer often have chronic lung disease, contributing to impaired CRF. Radiation to the heart during treatment of lung cancer may further reduce CRF. The determinants of reduced CRF in this population are not well understood. In this study, we sought to determine whether cardiac diastolic function, as assessed by Doppler echocardiography and N-terminal pro-brain natriuretic peptide (NTproBNP) levels, correlate with CRF as measured by peak oxygen consumption (VO 2 ), in patients with reduced lung function who received chest irradiation for lung cancer. We found that Doppler-derived measures of diastolic function and serum levels of NTproBNP inversely correlate with peak VO 2. In a multivariate regression model, NTproBNP was the strongest independent variable associated with peak VO 2 . These results suggest that diastolic dysfunction may further contribute to reduced CRF in patients with lung cancer who have received radiotherapy and have reduced lung function.

\section{Introduction}

Contemporary and sophisticated administration of thoracic radiotherapy has been effective in targeting tumor tissue while limiting exposure to the heart, yet studies have shown that symptoms of exercise intolerance seem to appear early after radiotherapy and contribute significantly to an impaired quality of life. ${ }^{1-3}$ Cardiorespiratory fitness, reflected in peak oxygen consumption $\left(\mathrm{VO}_{2}\right)$, refers to the integrated ability of the cardiovascular and respiratory systems to supply oxygen to skeletal muscles during sustained physical activity. Lung cancer survivors consistently demonstrate poor CRF and studies have shown a strong inverse relationship between peak $\mathrm{VO}_{2}$ and surgical outcomes, chemotherapy response, and survival. ${ }^{4-6}$

Pulmonary function testing using spirometry to measure the forced expiratory volume in the first second $\left(\mathrm{FEV}_{1}\right)$ of a forced vital capacity $(\mathrm{FVC})$ maneuver, is routinely measured in lung cancer patients in preparation for treatment and to identify high-risk patients requiring close follow-up. As expected, $F V_{1}$ is often reduced in lung cancer patients. Reduced $\mathrm{FEV}_{1}$ is strongly associated with mortality in these patients ${ }^{7}$ and has been shown to play an integral role in predicting peak $\mathrm{VO}_{2}{ }^{8}$

Natriuretic peptides, such as N-terminal pro-brain natriuretic peptide (BNP, NTproBNP), have also been shown to correlate with peak $\mathrm{VO}_{2}$ and are sensitive to change with interventions designed to improve CRF. ${ }^{9,10}$ Several studies have shown that in lung cancer patients, plasma levels of natriuretic peptides are elevated. ${ }^{11-13}$ In particular, lung cancer patients with no known risk factors for elevated NTproBNP $(\geq$ $125 \mathrm{pg} / \mathrm{mL}$ ), were seven times more likely to have an elevated NTproBNP.${ }^{12}$ Moreover, Maeder et al. showed that natriuretic peptides were independently associated with a significantly impaired peak $\mathrm{VO}_{2}$ in patients with lung disease. ${ }^{14}$ However, NTproBNP is not routinely measured in lung cancer patients, and the additive role of NTproBNP in those with reduced $\mathrm{FEV}_{1}$ remains unclear. 
In the present study, we sought to determine if peak $\mathrm{VO}_{2}$ is predicted by NTproBNP in lung cancer patients with reduced $\mathrm{FEV}_{1}$.

\section{Methods.}

A prospective study was performed at Virginia Commonwealth University (VCU) enrolling patients with a history of chest cancers who had received thoracic radiotherapy with a resultant significant cardiac dose ( $\geq 5$ Gy to $\geq 10 \%$ of the heart volume) with or without concurrent chemotherapy as part of curative treatment for malignancy. The main results of the study have been previously published. ${ }^{5}$ We herein present data on a sub-analysis of patients with lung cancer following completion of radiotherapy. All patients underwent informed consent prior to enrollment. The study was approved by the VCU Massey Cancer Center Protocol Review and Institutional Review Board.

Participants were lung cancer survivors who were at least 18 years of age, able to perform treadmill exercise testing, had normal renal function (glomerular filtration rate $>60 \mathrm{~mL} / \mathrm{min} / 1.73 \mathrm{~m}^{2}$ ) and were without a previously known diagnosis of cardiovascular disease or heart failure at the time of study enrollment. Subjects were evaluated with spirometry (including measurement of $\mathrm{FEV}_{1}$ ), echocardiography (including measurement of left-ventricular ejections fraction [LVEF]; the ratio of early mitral inflow velocity to mitral annular early diastolic velocity averaged between the septal and lateral annulus [E/e'] as an estimate of left-ventricular filling pressure; the tricuspid annular plane systolic excursion (TAPSE) and systolic velocity at tissue Doppler ( $\mathrm{S}^{\prime}$ ) as a measure of right ventricular (RV) function), cardiopulmonary exercise testing (peak $\mathrm{VO}_{2}$ ), and measurement of serum NTproBNP. Reduced $\mathrm{FEV}_{1}$ was defined as $<80 \%$ of predicted with a $F E V_{1} / F V C$ ratio $<0.7$. Radiation dose to the heart and lungs were determined by dosevolume histograms from the pre-treatment planning computed tomography scans.

Data are reported as median and interquartile range (IQR) or number (\%). Relationship between peak $\mathrm{VO}_{2}$ and other variables was determined by Spearman's correlation coefficients or Mann-Whitney test for dichotomous variables. To investigate independent predictors of peak $\mathrm{VO}_{2}$, we used a stepwise multivariate regression model including only identified clinical characteristics, spirometry, and echocardiography variables associated with a $P<0.05$ at univariate analysis. Statistical analysis was conducted with SPSS 26.0 (IBM Corp, Armonk, NY).

\section{Results}

We evaluated 15 patients that had received thoracic RT for the treatment of lung cancer (Table). Twelve of the fifteen (80\%) patients (9 [75\%] males, 64 [59-66] years of age) had reduced $\mathrm{FEV}_{1}$ values $(53 \%$, [42-66]). These 12 patients received 60.0 [51.0-65.3] Gy to the chest with a mean heart radiation dose of 10.5 [5.6-26.5] Gy, 2.7 [0.6-5.8] years earlier. None of the patients has a pre-existing history of heart failure or left ventricular systolic dysfunction. 
Peak $\mathrm{VO}_{2}$ was severely reduced ( $47[42-56] \%$ of predicted) and inversely correlated with $\mathrm{E} / \mathrm{e}^{\prime}$ and serum levels of NTproBNP ( $\mathrm{R}=-0.62, P=0.04$ and $\mathrm{R}=-0.85, P<0.001$, respectively). Peak $\mathrm{VO}_{2}$ also correlated with $\mathrm{FEV}_{1}(\mathrm{R}=+0.61, P=0.04)$, however in a multivariate regression model including $\mathrm{E} / \mathrm{e}^{\prime}, \mathrm{NTproBNP}$, and $\mathrm{FEV}_{1}, \mathrm{NTproBNP}$ was the only variable retained $\left(R^{2}=0.710\right.$, standardized $\left.-\beta=-0.843 ; P=0.001\right)$. Figure 1 illustrates the relationship between NTproBNP and peak $\mathrm{VO}_{2}$.

Peak $\mathrm{VO}_{2}$ was not associated with age, sex, race, $\mathrm{BMI}$, current smoking status or pack-year history, cancer stage, history of cancer surgery, chemotherapy use (Yes/No), carboplatin dose (most common chemotherapeutic [53\% use]), mean lung and cardiac radiation or total radiotherapy dose (all $P>0.10$ ). Furthermore, we found no correlation between the LVEF, TAPSE, or $S^{\prime}$ and peak $\mathrm{VO}_{2}$ (all $P>0.10$ ).

Elevated NTproBNP was significantly associated with a comorbid history of hypertension (117 [33-283] vs. 454 [245-649] pg/mL; $P=0.01)$. However, NTproBNP was not significantly associated with other potential risk factors for elevated NTproBNP such as FEV $1(R=-0.45, P=0.09), \operatorname{LVEF}(R=-.009, P=0.98)$, hemoglobin $(\mathrm{R}=-0.18, P=0.52)$, or history of liver disease $(P=0.83)$. NTproBNP showed a trend toward significant association with $E / e^{\prime}$ ratio $(R=0.582, P=0.06)$, which is a measure of diastolic dysfunction and elevated LV filling pressures.

\section{Discussion}

Cardiorespiratory fitness plays an important role in lung cancer morbidity, mortality and overall quality of life. ${ }^{2,4,7}$ In this study, we report that patients with early stage and locally advanced lung cancer with reduced pulmonary function, but without a known pre-treatment history of cardiovascular disease or heart failure, demonstrate elevated NTproBNP serum levels that predict peak $\mathrm{VO}_{2}$ following radiotherapy with and without chemotherapy. Our data suggest that biomarkers of cardiac function contribute to impaired CRF in patients with lung cancer in addition to pulmonary function, thus expanding our understanding of exercise intolerance in lung cancer. We can use this information to effectively screen lung cancer individuals with reduced $\mathrm{FEV}_{1}$ and assess serum NTproBNP levels to allow for early identification of patients that could benefit from medical management (i.e., introduction of neurohormonal antagonists or exercise training interventions) or monitoring to minimize morbidity, improve overall quality of life, and potentially improve longevity.

The mechanism(s) driving this remain unclear and likely multifactorial, but cancer-related inflammation is believed to be a large contributor. ${ }^{15}$ Right ventricular stress due to pulmonary pathology may also play a role.

We acknowledge that this sub-analysis has several limitations. First, this cohort included a small sample size. Second, we did not have pre-treatment (baseline) NTproBNP values for comparison, which would allow for direct comparison before and after treatment. Third, the diffusion capacity of the lungs for 
carbon monoxide was not measured in these patients, which may help elucidate key cardiac and pulmonary contributions to $\mathrm{CRF}$ in this population.

\section{Conclusion}

In stable patients with early and locally advanced lung cancer and reduced FEV $\mathrm{f}_{1}$, diastolic dysfunction contributes to impaired CRF and serum NTproBNP levels independently predict peak $\mathrm{VO}_{2}$. This emphasizes the contribution of cardiac function to CRF of these patients and proposes NTproBNP as a marker for patient prognostication and possible therapeutic intervention.

\section{Abbreviations}

$\mathrm{VO}_{2}$ : oxygen consumption; $\mathrm{mL} \cdot \mathrm{min}^{-1}=$ milliliters of oxygen per minute; $\mathrm{NTproBNP}=\mathrm{N}$-terminal pro-brain natriuretic peptide; $\mathrm{pg} / \mathrm{mL}=$ picograms per milliliter.

\section{Declarations}

Funding: This work was supported by a Virginia Commonwealth University Massey Cancer Center Pilot Project grant [P30CA016059K]. This study was also supported by a Center for Clinical and Translational Research grant [1UL1TR002649] to Virginia Commonwealth University, Richmond, Virginia, United States.

Disclosures: This study was supported in part by a National Center for Clinical and Translational Research Clinical and Translational Science Award [UL1TR002649] to Virginia Commonwealth University (PI: Frederick Moeller, MD). Dr. Weiss is supported by a grant from the National Institutes of Health [U01Al133595] to Virginia Commonwealth University. Dr. Carbone is supported by a Career Development Award [19CDA34660318] from the American Heart Association and by the Clinical and Translational Science Awards Program [UL1TR002649] from National Institutes of Health to Virginia Commonwealth University. Dr. Abbate is supported by a National Center for Clinical and Translational Research Clinical and Translational Science Award [UL1TR002649]. The other authors have nothing to disclose.

Conflicts of Interest: None.

Availability of data and material: Available upon request.

Code availability: Not applicable.

\section{References}

1. Atkins KM, Rawal B, Chaunzwa TL, Lamba N, Bitterman DS, Williams CL, Kozono DE, Baldini EH, Chen AB, Nguyen PL, D'Amico A V., Nohria A, Hoffmann U, Aerts HJWLWL, Mak RH. Cardiac Radiation Dose, Cardiac Disease, and Mortality in Patients With Lung Cancer. J Am Coll Cardiol. 2019;73(23):2976-2987. doi:10.1016/j.jacc.2019.03.500 
2. Wang K, Eblan MJ, Deal AM, Lipner M, Zagar TM, Wang Y, Mavroidis P, Lee CB, Jensen BC, Rosenman JG, Socinski MA, Stinchcombe TE, Marks LB. Cardiac Toxicity After Radiotherapy for Stage III Non-Small-Cell Lung Cancer: Pooled Analysis of Dose-Escalation Trials Delivering 70 to 90 Gy. J Clin Oncol. 2017;35(13):1387-1394. doi:10.1200/JC0.2016.70.0229

3. Yeh ETH, Vejpongsa P. Subclinical Cardiotoxicity Associated With Cancer Therapy: Early Detection and Future Directions. J Am Coll Cardiol. 2015;65(23):2523-2525. doi:10.1016/j.jacc.2015.04.012

4. Jones LW, Watson D, Herndon JE 2nd, Eves ND, Haithcock BE, Loewen G, Kohman L. Peak oxygen consumption and long-term all-cause mortality in nonsmall cell lung cancer. Cancer. 2010;116(20):4825-4832. doi:10.1002/cncr.25396

5. Canada JM, Trankle CR, Carbone S, Buckley LF, Chazal M de, Billingsley H, Evans RK, Garten R, Van Tassell BW, Kadariya D, Mauro A, Toldo S, Mezzaroma E, Arena R, Hundley WG, Grizzard JD, Weiss E, Abbate A. Determinants of Cardiorespiratory Fitness Following Thoracic Radiotherapy in Lung or Breast Cancer Survivors. Am J Cardiol. 2020;125(6):988-996. doi:10.1016/j.amjcard.2019.12.019

6. Brunelli A, Kim AW, Berger KI, Addrizzo-Harris DJ. Physiologic evaluation of the patient with lung cancer being considered for resectional surgery: Diagnosis and management of lung cancer, 3rd ed: American College of Chest Physicians evidence-based clinical practice guidelines. Chest. 2013;143(5 Suppl):e166S-e190S. doi:10.1378/chest.12-2395

7. Kang HS, Shin AY, Yeo CD, Kim JS, Kim YH, Kim JW, Lee SH. A lower level of forced expiratory volume in one second predicts the poor prognosis of small cell lung cancer. J Thorac Dis. 2018;10(4):21792185. doi:10.21037/jtd.2018.03.121

8. Hassel E, Stensvold D, Halvorsen T, Wisløff U, Langhammer A, Steinshamn S. Lung function parameters improve prediction of VO2peak in an elderly population: The Generation 100 study. PLoS One. 2017;12(3):e0174058. doi:10.1371/journal.pone.0174058

9. Williams SG, Ng LL, O'Brien RJ, Taylor S, Wright DJ, Li YF, Tan LB. Complementary roles of simple variables, NYHA and N-BNP, in indicating aerobic capacity and severity of heart failure. Int $\mathrm{J}$ Cardiol. 2005;102(2):279-286. doi:10.1016/j.jijcard.2004.05.054

10. Maria Sarullo F, Gristina T, Brusca I, Milia S, Raimondi R, Sajeva M, Maria La Chiusa S, Serio G, Paterna S, Di Pasquale P, Castello A. Effect of physical training on exercise capacity, gas exchange and $\mathrm{N}$-terminal pro-brain natriuretic peptide levels in patients with chronic heart failure. Eur $\mathrm{J}$ Cardiovasc Prev Rehabil. 2006;13(5):812-817. doi:10.1097/01.hjr.0000238396.42718.61

11. Otsuka T, Nojiri T, Minami S, Hosoda H, Kuroyama M, Hirata H, Nakanishi K, Yamamoto S, Komuta K, Kangawa K, Kijima T. Evaluation of Natriuretic Peptide in Non-small Cell Lung Cancer Patients Treated with Bevacizumab Together with Carboplatin-Paclitaxel: A Prospective Study. Anticancer Res. 2017;37(7):3505-3512. doi:10.21873/anticanres.11718

12. Aujollet N, Meyer M, Cailliod R, Combier F, Coignet Y, Campard S, Facy O, Bernard A, Girard C. High Nterminal pro-B-type natriuretic peptide: a biomarker of lung cancer? Clin Lung Cancer. 2010;11(5):341-345. doi:10.3816/CLC.2010.n.043 
13. Omersa D, Cufer T, Marcun R, Lainscak M. Echocardiography and cardiac biomarkers in patients with non-small cell lung cancer treated with platinum-based chemotherapy. Radiol Oncol. 2017;51(1):1522. doi:10.1515/raon-2016-0037

14. Maeder MT, Brutsche MH, Christ A, Reichlin T, Staub D, Noveanu M, Breidthardt T, Potocki M, Mueller C. Natriuretic peptides for the prediction of severely impaired peak $\mathrm{VO}_{2}$ in patients with lung disease. Respir Med. 2009;103(9):1337-1345. doi:10.1016/j.rmed.2009.03.015

15. Canada JM, Thomas GK, Trankle CR, Carbone S, Billingsley H, Van Tassell BW, Evans RK, Garten R, Weiss $\mathrm{E}$, Abbate A. Increased C-reactive protein is associated with the severity of thoracic radiotherapy-induced cardiomyopathy. Cardio-Oncology. 2020;6(1):2. doi:10.1186/s40959-020-00581

\section{Tables}


Table. Cohort Characteristics.

\section{Variable}

Age, years

Women

Race

Caucasian

African American

Body Mass Index, $\mathrm{kg} / \mathrm{m}^{2}$

\section{Smoking status}

Lifetime

Current

Lung Cancer type

SCLC

NSCLC

Squamous

Adenocarcinoma

TNM Stage at diagnosis
Stage 1

Stage 2

Stage 3

Treatment type

Radiotherapy

Surgery prior to radiotherapy

Chemotherapy

Immunotherapy

Total radiation dose, Gy

Mean cardiac dose, Gy

Mean lung dose, Gy
Cohort $(\mathrm{N}=12)$

$64(59-66)$

$3(25 \%)$

$7(58 \%)$

$5(42 \%)$

$23.7(20.8-27.1)$

$12(100 \%)$

$5(42 \%)$

$1(8 \%)$

$11(92 \%)$

$7(50 \%)$

$4(50 \%)$
$1(8 \%)$

$1(8 \%)$

$10(83 \%)$

$12(100 \%)$

$2(17 \%)$

10 (83\%)

$1(8 \%)$

$60.0(51.0-65.3)$

10.5 (5.6-26.5)

$14.0(8.0-17.1)$ 
Table. Cohort Characteristics.

Peak VO $2, \mathrm{~mL} \cdot \mathrm{min}^{-1}$

971 (769-1318)

$\%$-predicted peak $\mathrm{VO}_{2}$

$47(42-56)$

LVEF, \%

$52(40-59)$

$E / e^{\prime}$

$9.4(8.4-13.3)$

NTproBNP, pg/mL

$344(86-468)$

NTproBNP $\geq 125 \mathrm{pg} / \mathrm{mL}$

$10(83 \%)$

FEV $_{1}$, Liters

$1.36(0.98-2.30)$

$\mathrm{FEV}_{1}, \%$-predicted

$53(42-66)$

$\mathrm{FEV}_{1} / \mathrm{FVC}$ ratio

$0.55(0.43-0.61)$

Date are listed as median (IQR) or number (\%). Abbreviations: SCLC $=$ small cell lung cancer; NSCLC = non-small cell lung cancer; $\mathrm{TNM}=$ tumor $/$ node/ $/$ metastasis; $\mathrm{Gy}=$ Gray units; $\mathrm{VO}_{2}=$ oxygen

consumption; $\mathrm{LVEF}=$ left ventricular ejection fraction; $\mathrm{E} / \mathrm{e}^{\prime}=$ ratio of early mitral inflow velocity to mitral annular early diastolic velocity; NTproBNP $=\mathrm{N}$-terminal pro-brain natriuretic peptide; $\mathrm{FEV}_{1}=$ forced-

expiratory volume at 1 -second; $F V C=$ forced vital capacity.

Figures
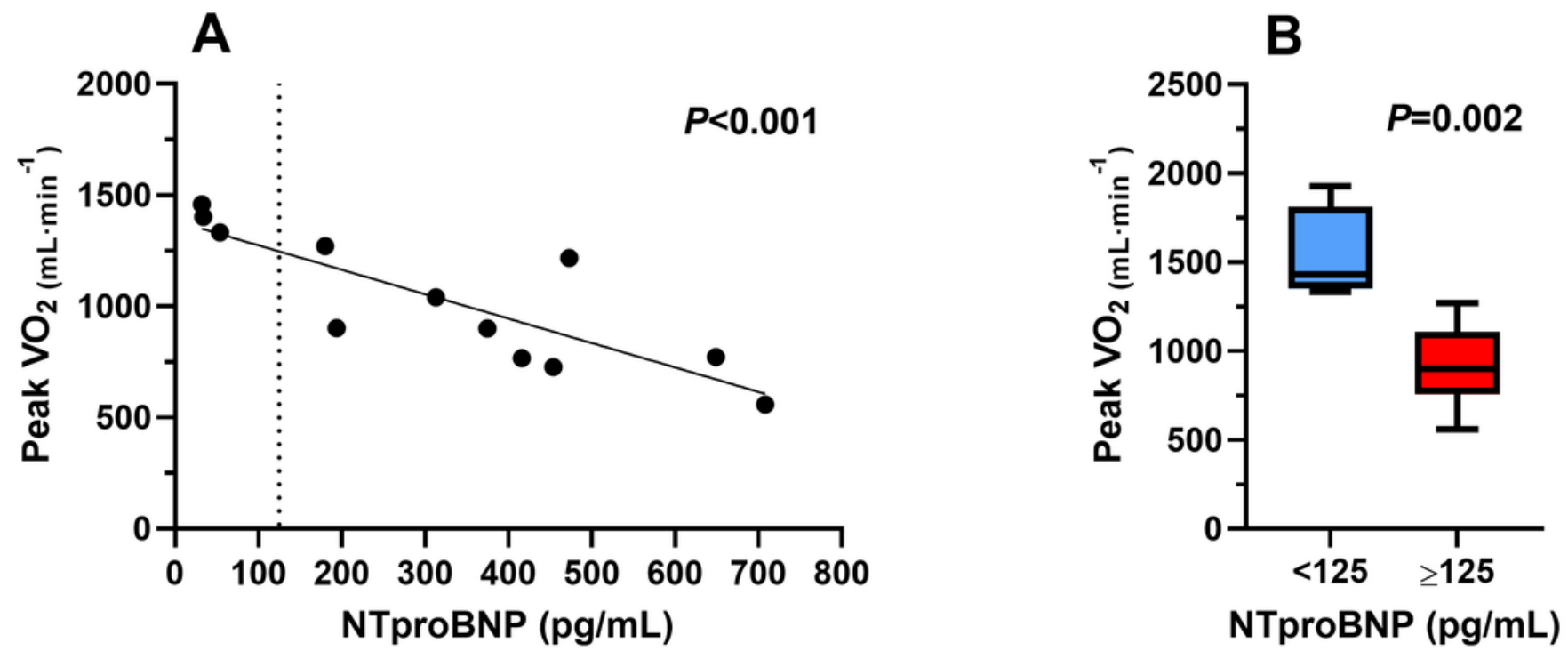

Figure 1 
Panel A: Regression slope between peak VO2 and NTproBNP in lung cancer patients with FEV $1<80 \%$ of predicted. Panel B: Box-Whisker plot of peak VO2 in those with NTproBNP $<125$ or $\geq 125 \mathrm{pg} / \mathrm{mL}$. Abbreviations: $\mathrm{VO} 2=0$ xygen consumption; $\mathrm{mL} \cdot \mathrm{min}-1=$ milliliters of oxygen per minute; $\mathrm{NTproBNP}=\mathrm{N}$ terminal pro-brain natriuretic peptide; $\mathrm{pg} / \mathrm{mL}=$ picograms per milliliter. 